\title{
Implementation of executive information systems around traditional manufacturing control system packages
}

\section{J. Fisher and $A$ K Kochhar}

Department of Mechanical Engineering

UMIST

Manchester M60 1QD, United Kingdom.

Tel: +44 (0) 1612003801 Fax: +44 (0) 1612008721

Email: mcjmscc@umist.ac.uk

\section{Reilley}

Manufacturing Products and Services Limited

The Coach House

Drighlington, West Yorkshire BD11 LN

United Kingdom.

Tel: +44 (0) 1132853385 Fax: +44 (0) 1132852636

Email:miker@maps.co.uk

\begin{abstract}
In common with most traditional data processing systems, a vast majority of manufacturing control systems' packages simply process and store large amounts of manufacturing data. This data can hold significant strategic value for an organization if it can be transformed into meaningful information.
\end{abstract}

This paper describes the main features of a prototype executive information system, based on the application of On-Line Analytical Processing techniques for extracting strategic performance data, suitable for making executive decisions, from standard manufacturing control system databases. The results of critical evaluation by users are described.

\section{Keywords}

Manufacturing control systems, Performance measurement, Executive information systems, On-line analytical processing. 


\section{INTRODUCTION}

Within manufacturing organizations, often one of the largest and most important sources of information is the manufacturing planning and control (MPC) system. MPC systems are concerned with the planning and control of the manufacturing process, and an effective MPC system can provide substantial strategic advantage for a company in its markets (Vollman 1992). Although activities within manufacturing planning and control can be undertaken manually, the complexity of modern day systems demands the use of computers to manage them effectively. Such systems are, by their very nature, both consumers and creators of detailed operational data. They are vital for the daily running of organizations but are not appropriate for establishing the overall picture, making comparisons and deciding on change (Kelly 1996).

In efforts to provide solutions to the maze of information held within organizations, information regarded to be of strategic importance to decision making has been presented to executives by means of computerized executive information systems (EIS). These systems, originally aimed solely at executives, provide highly summarized information in a graphical and/or textual format. Such systems have achieved various levels of success (Taylor 1994, Nord 1995) at addressing the needs of executives, but have been fairly inflexible in being able to manipulate data for more detailed analysis.

\section{ON-LINE ANALYTICAL PROCESSING}

OLAP (On-Line Analytical Processing) is a new name for a set of proven concepts. The concept that most distinguishes OLAP from many other decision support categories is that of multidimensionality. Instead of the information being arranged in a set of flat tables or spreadsheets, multidimensional models present data in terms of the actual business dimensions of an organization. This is the type of analysis required by both managers and executives, so as to assess the variables which effect the performance of their organizations. OLAP is now becoming the technique used for data access and manipulation within EIS (Messina 1995, Ferguson 1996).

As the OLAP approach is amenable to providing a flexible, top down, view of an organization, it is postulated that it would be appropriate to apply OLAP to provide information relating to functions carried within manufacturing planning and control systems. By presenting a set of performance measures which are of strategic benefit to an organization, managers should be able to make more informed and timely decisions thus providing strategic advantage for their organizations. This paper describes a prototype Executive Information System, interfaced to an existing MRPII system, to obtain a variety of information in a very flexible manner. 


\section{SYSTEM INVESTIGATION AND DEVELOPMENT}

The prototype executive information system has been developed within a research group consisting of an academic institution, two software houses and a manufacturing company, to assess the potential of the approach. It is based around a traditional MRPII framework. Within this framework, the prototype was developed around the key areas of inventory control and purchasing. A survey was conducted within the manufacturing company. This was designed to determine typical performance measures which were used to judge the performance of the company and the resulting actions taken, and assess the usefulness of an EIS and the types of analysis and features which would be of benefit.

The findings of the surveys are summarized below:

- Few measures used to assess the performance of the company related to operational activities. Instead they concentrated on broad financial issues and did little to help identify sources of problems. Measures used to assess performance provided a fixed picture and did not stimulate action

- Large numbers of reports were generated and filed with no specific aim in mind

- EIS would provide a useful means of only retaining data useful for specific purposes

- Drilling down through various layers of information would provide the greatest benefit in identifying problems and opportunities.

Perhaps the most important conclusion from the survey was:

"A manageable set of performance measures is required which will be of practical use in establishing the route causes of problems and which provide a true representation of an organization. The measures should be represented in an easy to understand format in a timely manner".

\section{Executive Information System Development}

The development of the EIS essentially involved a two stage process. Firstly, an initial set of performance measures was developed which aimed to illustrate the activities of the areas under investigation. From this initial set of measures, attention was then focused on how they could be represented using multidimensional analysis, employing on-line analytical processing (OLAP). 


\section{Development of Performance Measures}

The initial set of performance measures for inventory control is shown in Table 1.

\begin{tabular}{|c|c|}
\hline Measure & Objective \\
\hline Service Level & $\begin{array}{l}\text { Measures parts that are available in the } \\
\text { stores when required }\end{array}$ \\
\hline Parts availability & $\begin{array}{l}\text { Measures the level of availability of } \\
\text { parts }\end{array}$ \\
\hline Customer dissatisfaction & $\begin{array}{l}\text { Measures the number of customers } \\
\text { suffering from unavailability of parts in } \\
\text { a given period }\end{array}$ \\
\hline Inventory accuracy & Measures the accuracy of stock records \\
\hline Sequencing of parts issue & $\begin{array}{l}\text { Measure how well stock issuing } \\
\text { procedures are followed }\end{array}$ \\
\hline Shelf life control & $\begin{array}{l}\text { Measures how much stock is wasted } \\
\text { due to expiry of shelf life }\end{array}$ \\
\hline Time a part is in stock & $\begin{array}{l}\text { Determines slow moving or obsolete } \\
\text { stock }\end{array}$ \\
\hline $\begin{array}{l}\text { Increase in inventory levels as a } \\
\text { proportion of rate of increase of sales }\end{array}$ & $\begin{array}{l}\text { Measures contribution of increased } \\
\text { level of inventory to sales }\end{array}$ \\
\hline Average value of inventory & Measures the value of inventory held \\
\hline Inventory turnovers & $\begin{array}{l}\text { Measures the frequency with which } \\
\text { inventory is turned over }\end{array}$ \\
\hline Frequency of stockouts & $\begin{array}{l}\text { Measures how often parts are } \\
\text { unavailable in inventory and thus cause } \\
\text { disruptions to production }\end{array}$ \\
\hline
\end{tabular}

Table 1. List of Performance Measures for Inventory Control

\section{Model Design}

For the system to be considered as a beneficial and effective tool, the following functional requirements were specified:

1. Managers and executives should be able to rapidly access information relating to pre-defined performance measures, as well as perform ad-hoc enquiries from information available within the MPC system. This information should be presented in a variety of formats.

2. The system should provide relevant information which can be used to aid in making more informed decisions.

3. The system should be reasonably simple and straightforward to use. 
4. Simple navigation through different business dimensions should be provided to enhance the ease of use.

5. Highlighting of exceptional information should be available to draw the attention of the user to important issues.

\section{Conceptual Design}

The system is modular in design (Figure 1), so that individual components can be modified without affecting others, and to facilitate future development. Individual elements of the system are now discussed.

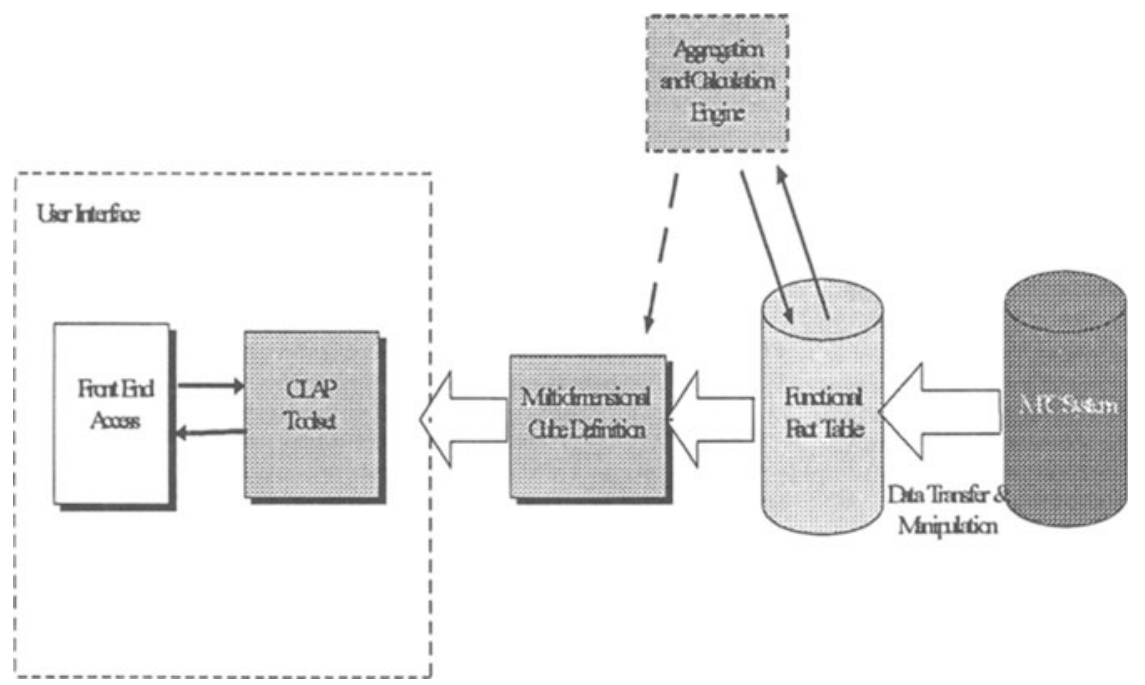

Figure 1. Representation of System Architecture

\section{MPC System}

The MPC system is the operational system from which manufacturing data is extracted. It consists of a number of different relational tables containing transactional information. In this form the data provides little value for decision making. The data required by the EIS, typically resides in a number of different tables within the MPC system. It is therefore necessary to create links between these tables so that the appropriate data may be extracted. The data held within the MPC system may also require a certain amount of manipulation before it can be extracted. 


\section{Functional Fact Table}

Although the system uses the same data as the MPC system, it does not use the same image of it. Data is extracted from the operational system, manipulated as required and stored in tables relating to the specific function module. These tables, called functional fact tables, are used by the analysis tools as their source of information.

\section{Aggregation and Calculation Engine}

The aggregation and calculation engine (ACE) is used to populate the fact tables with pre-aggregated data for hierarchical dimensions and pre-calculated data for equations. ACE allows for the aggregation of the complete data set, or if required, a subset of the original.

\section{Multidimensional Cube Definition}

The multidimensional cube definition involves the creation of a definition 'layer' of the existing functional fact tables. The layer is in essence a mapping process whereby fields are identified within the fact tables and are mapped onto master tables. Each master table is equivalent to a dimension within the cube definition.

\section{OLAP Toolset}

The OLAP toolset is the main element of the system with which the end-user comes into contact. Users are able to view multiple charts and reports, rotate dimensions, drill up or down, rank information, highlight variances, change presentation formats and define new calculations.

\section{Front-End Access}

The front-end access provides a simple method to access the OLAP toolset through a Windows environment. Access is obtained by clicking on an icon.

\section{Example}

The application of the system is perhaps best illustrated by means of an example. One of the multidimensional 'cubes' relates to inventory movement around the system. Within the cube definition process, a graphical entity relationship diagram (ERD) is used to illustrate the relationship between dimension tables and central fact table. The multidimensional model provides a representation of all the relationships between different dimensions and portrays the types of analysis available. Figure 2 shows the entity relationship diagram for the inventory movements cube which is used for the analysis of raw materials and components control. The dimension tables contain information which describes the transaction data held in the fact table, or transaction file. As each cube has only one fact table, the cube definition can be said to have a 'one-to-one' relationship with the fact table. 


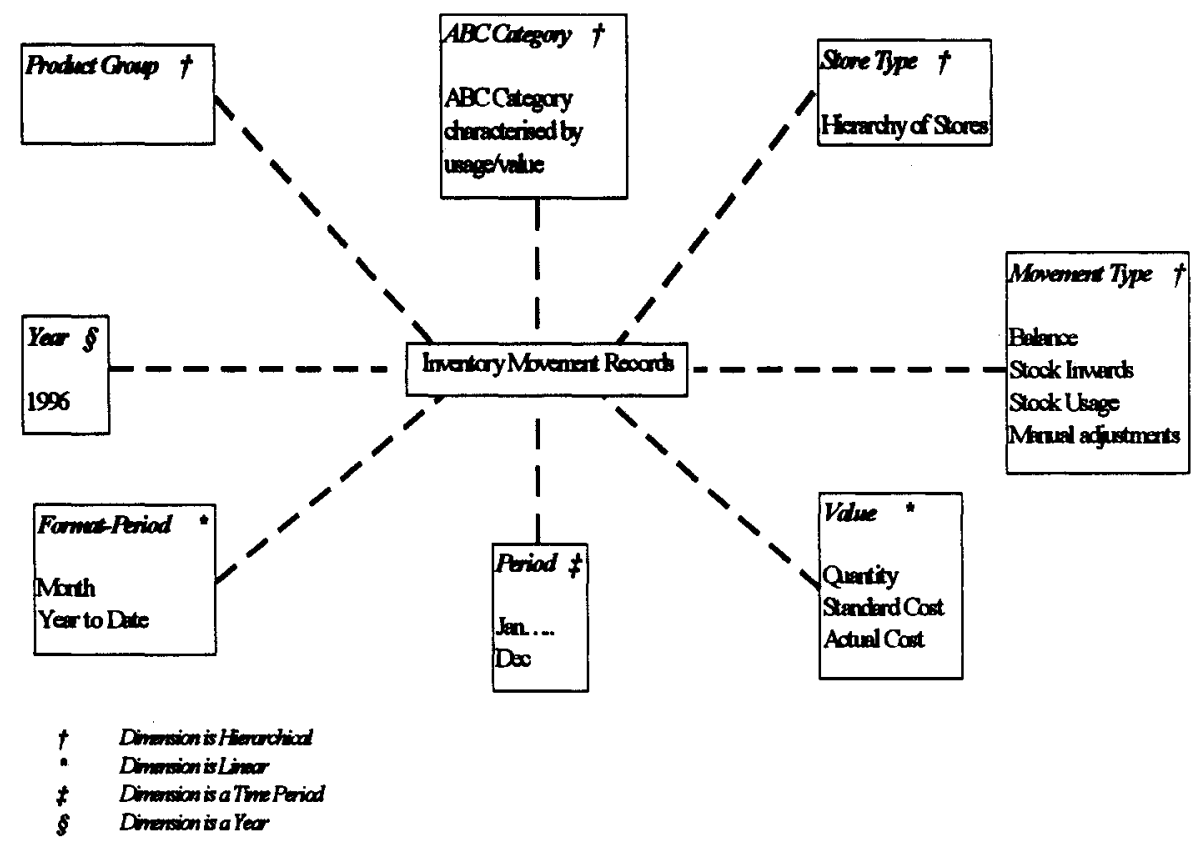

Figure 2. Entity Relationship Diagram for Inventory Movements Cube

The objective of the cube is to provide analysis relating to the dynamic inventory movements by utilizing data held within stock movement records. Analysis can be conducted for any combination of the dimensions shown in figure 2.

There are essentially two types of dimension, either 'list' or 'hierarchical.' List type dimensions are a simple list and are straight forward. However hierarchical dimensions contain a parent/child structure where data for parent items is aggregated across several child items. When specifying hierarchical dimensions, it is necessary to define the parent item of each child. For example, figure 3 illustrates the hierarchy for a dimension containing stock movement types, as taken from the inventory movements cube. 


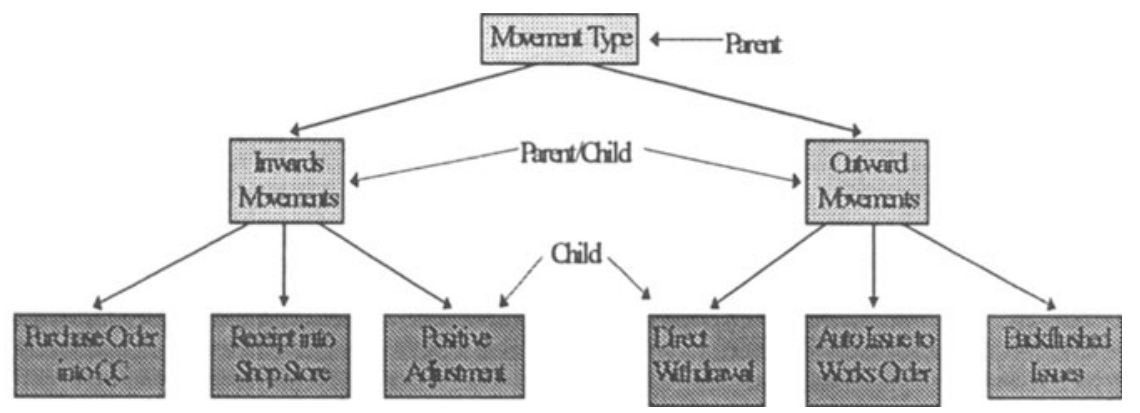

Figure 3. Example of a hierarchical dimension containing details of movement types.

\section{System Implementation}

The whole system has been implemented in a Windows environment and presents information in a highly visual and easily understandable environment. The system has an open architecture in that it can access information from any standard relational database. On-line analytical processing (OLAP is used to analyze the data so as to present meaningful information to users.

\section{SYSTEM ASSESSMENT}

The assessment of the system was carried out by means of a multi-part questionnaire, and feedback was obtained from a number of potential users. The results of the assessment are summarized below:

- It is possible to view manufacturing data in a way which has previously been unavailable from MPC systems.

- Companies are being run by fewer people who require information on the performance of their companies in a format which allows different perspectives of it to be analyzed.

- The EIS system developed represents the activities which occur within the areas under investigation effectively, and provides relevant and useful information which can be used to highlight problems and aid in decision making.

- The level of detail of the information is sufficient for general analysis, but more detailed information is required to identify individual problems.

- The facilities of drill down and exception reporting were considered to be of most benefit to people when analyzing data.

\section{CONCLUSIONS}

OLAP is very much user driven. It is not of great benefit if what is required is a rigid set of reports which present a fixed set of performance measures. The strength of this approach lies within the ability to view data from a number of 
different perspectives and thus navigate through different data slices. From the models developed during this research, a number of conclusions can be drawn with respect to the suitability of presenting performance measurement information using OLAP:

- OLAP provides an effective way of presenting manufacturing data, in a simple, intuitive form, and provides powerful manipulation and analysis of such data.

- Not all types of performance measures are conducive to multidimensional analysis. As the range of dimensions restricts the scope of the analysis, it is necessary to assess the benefits which would be attained from representing information multidimensionally, and the costs required to create the cubes.

- Cubes should be developed to incorporate those measures which are of greatest importance to a company.

- As the number of unrelated dimension items increases, sparsity within the models increases exponentially.

- The manufacturing data itself must be accurate and used in the way it is intended, for the system to be useful.

\section{REFERENCES}

Kelly, S. [1996] Data Warehousing: The Route to Mass Customization. John Wiley \& Sons.

Ferguson, N. [1996] The Data Warehousing Boom, Conspectus, February, 2-5.

Messina, F. M.; Singh, S. [1995] Executive Information Systems: Not just for Executives Anymore!, Management Accounting, July, 60-63.

Nord, J. N.; Nord, G. D. [1995] Why managers use executive support systems, Industrial Management and Data Systems, 95 No. 9, 24-28.

Taylor, D. [1994] EIS is Dead, Long Live EIS, Technology, Management Today, May, 89.

Vollman T. E.; Berry W. L.; Whybark D. C. [1992] Manufacturing Planning and Control Systems. Irwin.

\section{BIOGRAPHY}

Jim Fisher holds a Bachelor's Degree in Mechanical Engineering from the University of Nottingham, and a Master's Degree in Advanced Manufacturing Technology and Systems Management from UMIST. He is currently a Manufacturing Engineering at Rover Group Limited.

Ashok Kochhar is the Lucas Professor of Manufacturing Systems Engineering, and Head of the Manufacturing Division at the University of Manchester Institute of Science and Technology (UMIST). His main research interests are in the areas of Competitive Manufacturing, Manufacturing Control Systems, Performance Measurement and Benchmarking. 
Mike Reilly is the Principal Manufacturing Consultant at Manufacturing Products and Services (MAPS) who are one of the UK's leading developers and providers of Manufacturing Control Systems. 